\title{
ÓSCAR WILDE (1854-1900): DEL ARTE POR EL ARTE A UNA CENA CON PANTERAS.
}

POR RODRIGO QUESADA MONGE ${ }^{1}$.

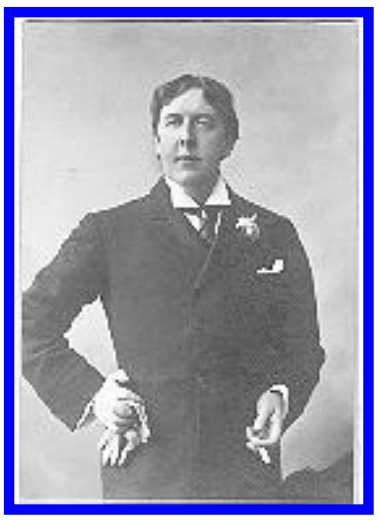

"And all men kill the thing they love, By all let this be heard, Some do it with a bitter look, Some with a flattering word. The coward does it with a kiss, The brave man with a sword!"

\section{NOCIONES PRIMIGENIAS.}

Hablemos de Óscar Wilde (1854-1900). Pero hagámoslo con la alegría de quien se prepara a dedicar una canción, una canción para uno de los más grandes poetas de este siglo, y por lo tanto, uno de los más agudos y lúcidos visionarios de nuestra época. Porque, entre la tristeza y el gozo, la gloria y la miseria, el triunfo y la caída, la figura de Wilde se yergue grande y aleccionadora por dondequiera que se la mire.

A contra pelo del canon victoriano, es decir, del conjunto de creencias y principios que regían el gusto artístico y la conducta moral de los ingleses, durante el reinado de la adusta e hierática reina Victoria (1837-1901), uno tiene la dicha reservada y discreta de encontrarse con espíritus aventureros y osados, como Wilde, que se atrevieron a tomar tales convencionalismos y reglas por los pelos, para lanzarlos por encima de la borda de un programa socio-ideológico, que no sólo era fiel tributario de la corona sino también de las estructuras imperiales.

En la condena de Wilde a dos años de trabajos forzados por sodomía, confluyen la hipocresía moral, el cinismo político, la prepotencia colonialista y finalmente la más 
desproporcionada intolerancia que uno pueda imaginarse. Mientras la corona británica hace todo lo posible por destruir a Wilde, siete años después de muerto éste, en la más absoluta soledad, en el medio de la pobreza y de la sequía artística, la corona sueca premia con el Nobel de Literatura a Rudyard Kipling (1865-1936) por su obediencia al canon victoriano, y por su lucidez en la defensa de los derechos que tienen los países “civilizados” para someter a los que no lo son, como los de África, Asia y América Latina ("la carga del hombre blanco", decía él)".

A cien años de su muerte, recordar a Wilde no es gratuito, no se trata de una simple pose académica, o porque nos obsesionen las efemérides. Cuando algunos, desde una posmodernidad vulgar y vana, quieren decirnos que el arte no sirve para nada, es el momento de preocuparnos, puesto que está a la vuelta de la esquina la posibilidad de que también nos digan que el humanismo ya perdió vigencia. Así lo han intentado con la herencia del marxismo y de las distintas variantes del pensamiento socialista, y casi lo han logrado con los anhelos de las personas por soñar y construir utopías cotidianas, uno de los grandes legados del siglo XIX, ese siglo burgués por excelencia, con todas sus contradicciones, pasiones y desgracias.

De tal forma que, hablar, pensar, sentir a Óscar Wilde desde este siglo brutal, sangriento y opresivo, no es baladí, es una necesidad. Puesto que su frescura, su alegría, su capacidad de sufrimiento y su ciclópeo coraje son una lección descomunal para todo aquél que crea en la más simple de las virtudes humanas: la honradez.. 


\section{ÓSCAR WILDE: EL HOMBRE.}

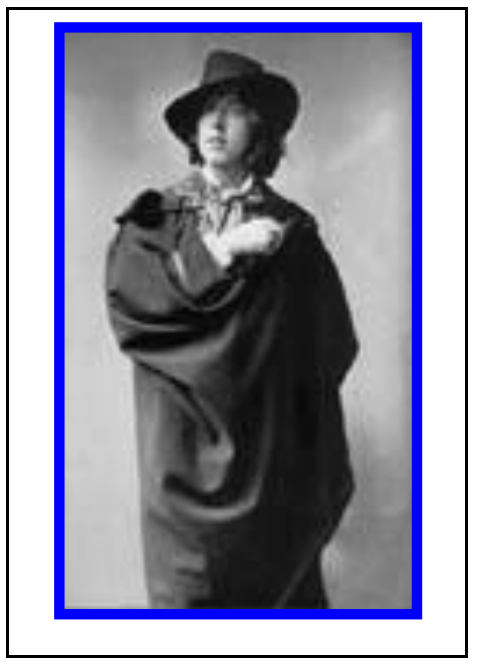

"De Irlanda por raza, y de Oxford por cultura", como solía decir de un amigo suyo, a Wilde se le puede visualizar de largo, como el prototipo del hombre moderno: repleto de contradicciones, y sin embargo, portador de una sustancial capacidad para soñar. Esa constante disposición al desafío lo puso frente a frente con una masa informe de reglas, normas y prohibiciones, que a la larga terminarían por aplastarlo.

Uno lo encuentra en los patios, jardines y plazoletas de la vetusta universidad de Oxford, engalanado de poses y mascaradas, jugando a la mediocridad, cuando en realidad sabemos que su inteligencia y sensibilidad estaban por encima de las de cualquier hombre o mujer de su tiempo. Pero el juego era muy peligroso, porque se trataba de manipular al medio y a los otros con simulaciones, pequeñas traiciones, jugarretas y paradojas, que buscaban tentar la curiosidad del amigo, del vecino, del lector, en una tómbola abigarrada de enigmas y acertijos que a él mismo lo dejarían sin salida alguna. Nos estamos refiriendo a que Óscar Wilde se construyó con esmero y dedicación su propio laberinto, según el buen entender de los griegos, a quienes tanto tradujo y amo $\boldsymbol{t}^{5}$. "Con frecuencia ocurre, nos decía, que cuando creemos que estamos experimentando con los otros, es con nosotros mismos con quienes lo hacemos en realidad".

Ni duda cabe de que Wilde con ese amor por la simulación anunciaba con mucho algunas de las tendencias más notables de la estética del siglo XX. Tanto así que, a 
veces sus tesis casi configuran un programa existencial, muy bien articulado en ciertos de sus más profundos ensayos, conferencias, diálogos y artículos, como lo veremos luego. Pero a Wilde le estaba reservado convertirse en la víctima propiciatoria que pusiera en evidencia toda la hipocresía pantagruelesca del reinado de Victoria. Pocas veces podemos encontrar una reina más consciente de su "misión civilizadora” como esta mujer. La magnificencia con que el totalitarismo victoriano fue construido, no sólo revela la incontrovertible vocación dictatorial de la mayor parte de las monarquías imperialistas de la época, sino que también permite explicar en gran parte algunas de las causas del cataclismo de la Primera Guerra Mundial (1914-1918).

Para Victoria y los ideólogos victorianos, los "súbditos" de su majestad no tenían vida privada. Todos y cada uno de los más ocultos resquicios de su cotidianidad estaban reglamentados, al extremo de que hasta las escaramuzas de alcoba debían sujetarse a cierto tipo de codificación ${ }^{7}$. Pero es que le tocó en suerte a su reinado, definir los parámetros con que se construiría y se cimentaría el imperio. No se podía pedir moral, disciplina, civilización y otros principios a los pueblos de África, Asia o el Caribe, sino se era capaz de construir una moral igualmente efectiva en casa.

Resulta que Óscar Wilde, su persona, sus ideas, sus emociones, sus gustos y hasta sus gestos no encajaban en ese esquema. Dos cosas entonces, parecen aflorar aquí con una fuerza particular, si algo queremos entender de la saña y la brutalidad con que se le reprimió, y finalmente se le aniquiló. Su homosexualidad por un lado, y sus ideas socialistas por otro, eran dos ingredientes definitivos para que todo el peso del canon disciplinario victoriano le cayera encima. Al lado de estos elementos, todo el dispositivo caricaturesco que Wilde montó con su dramaturgia sobre la moralidad burguesa, le 
representó en todo momento serios problemas éticos, políticos, estéticos y sociales. Porque las críticas de Wilde son anti-burguesas, más que anti-victorianas. Tenía claro que la monarquía era el obediente instrumento de un todo más abrumador y destructivo: la civilización capitalista. La monarquía y el imperio eran sus dos puntas de lanza, a las cuales, un autor como Kipling, siempre rindió respeto y pleitesía.

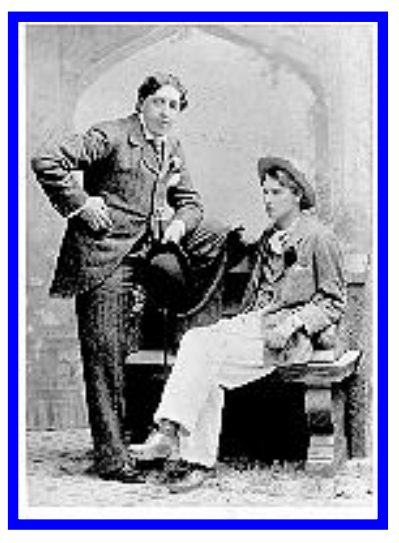

La homosexualidad de Wilde pareciera tener dos dimensiones, a cual más problemática y llena de riesgos. Bien podemos decir que es la primera víctima de la homofobia burguesa, pero también de aquella ajustada y apremiada por la racionalidad excesiva que ha caraterizado toda la época moderna. La racionalidad burguesa no aceptará nunca al homosexual pues éste está en contra de todos sus más caros principios: la familia por ejemplo, para la salud de la cual es necesaria la reproducción; la sexualidad displicente y mecánica, para la cual el cuerpo femenino no es asunto de las mujeres sino de la burguesía, que lo concibe como el depositario cierto de su visión material y espiritual del mundo. Por eso es que la rebeldía feminista en gran parte empieza por el rescate y recuperación de su propio cuerpo ${ }^{8}$.

Todo el basamento judeo-cristiano sobre el cual reposa la moral burguesa cruje ante la presencia insolente y vanagloriosa de un homosexual como Óscar Wilde. Hitler, Stalin, Somoza, Duvalier, todos los grandes dictadores de nuestra época persiguieron y aniquilaron cualquier brote de homosexualidad en sus sociedades. Y la reina Victoria, entre otros tiranos, les enseñaron cómo hacerlo. Rodeado de un séquito sumiso e incondicional de burócratas y policías, el dictador, el tirano, sea éste hombre o mujer, 
quiere controlar todos los detalles del funcionamiento de su sociedad. Y no hay cosa más difícil de controlar que la sensualidad, el erotismo, las espontaneidad de las pasiones. Éstas son increíblemente subversivas, trátese de una pareja homosexual o heterosexual. Resulta que la burguesía descubrió al individuo pero le negó su individualidad, de tal forma que su sexualidad es un asunto social, no lo es privado. Un homosexual entonces es un individuo marginal, un enfermo, que debe ser aislado para proteger la individualidad de los otros, aunque ese individuo en particular, deba ser eliminado. Aquí se trata de una decisión, como bien puede verse, muy civilizada, prendida del sano objetivo de proteger la "salud mental" del grupo, el cual, a la larga, para la burguesía, es simplemente una suma de individuos no de individualidades, como ya anotamos.

Entonces, para bien de la civilización, un homosexual, inteligente, sensible y educado como Wilde es peligroso, subversivo, revolucionario enventualmente, porque es portador de una individualidad demasiado fértil y vigorosa. Al fin y al cabo el sistema aniquila al individuo, pero la herencia de su individualidad es lo mejor que nos queda, y sobre eso no se discute porque al final de la jornada también se puede subastar. No es desarmonioso en consecuencia, pero sí muy irónico, que el inventor de las reglas para el boxeo, un deporte tan varonil y "machista", el Marqués de Queensberry, padre de Lord Alfred Douglas, amante y motivo de la tragedia de Wilde, fuera quien finalmente lo enviara a la cárcel.

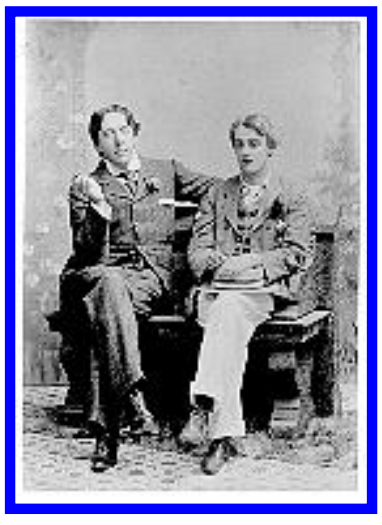

En conclusión, la moral burguesa primero arrincona al individuo, cuando a éste se le ocurre desafiar su indubitable dominación, para luego someter a escrutinio su individualidad. 
Si la herencia factible que ésta posibilita puede pasar a formar parte del acervo cultural de la civilización capitalista, entonces la burguesía termina merodeando esa herencia, se la apropia y la hace suya, es decir, la convierte en mercancía. En el caso de Óscar Wilde, como de muchos otros grandes artistas, individuo e individualidad son inseparables, aunque la moral burguesa los obligue a realizar una vida en el "closet". Mucha de la más bella poesía o de las cartas escritas por Wilde son directamente proporcionales a su naturaleza sexual. Ignorar ésto es separar al hombre del artista, una aberración que hoy nos hemos acostumbrado a ver con una gran naturalidad.

Pero junto al sufrimiento que tal desgarre produce, en términos humanos y artísticos, existe otro todavía más grave y de mayor impacto sobre la vida personal y social del artista. Esta es la otra dimensión de la homosexualidad de Wilde a la que queríamos referirnos también. Él lo describía maravillosamente, cuando decía que bajar a los mundos subterráneos de la prostitución masculina del Londres victoriano, era como “cenar con panteras", puesto que siempre se exponía al zarpazo, al chantaje que tales licencias suponían a manera de resaca ineludible. En estos viajes demenciales y arriesgados siempre lo acompañó Lord Alfred Douglas (1870-1945), Bosie.

Del paso de las tranquilas plazoletas del verde y aristocrático Oxford, al sucio y desvencijado Londres, Wilde y Douglas hicieron una aventura. La misma que los llevaría a la tragedia, la desgracia, la humillación y finalmente al desamor y al odio. Estas aventuras, aparentemente traviesas y juguetonas, tienen un perfil terrible, si pensamos en que, el que hacía las mayores apuestas era Wilde.

El tránsito de la homosexualidad como tragedia del pensamiento y la cultura, a la homsexualidad como comedia, proxenesis y vicio, les resultó a ambos amantes 
increíblemente caro. Ese juego camaleónico, esa mascarada sibilante repleta de entuertos e infortunios, tendría que sostenerse indefectiblemente en los bordes de la moral burguesa, la que no comprendería jamás ese ir y venir entre las dos caras de una homosexualidad diseñada para ocultar el verdadero propósito de toda esta aventura: encontrarle sitio al arte en una sociedad que hacía mucho rato había dejado de entenderlo. Creemos que Lord Alfred Douglas tampoco comprendió en toda su justa dimensión este azaroso manipular de espejos en que lo había metido Wilde.

Para él el juego tenía dirección sólo en la medida en que su individualidad artística saliera fortalecida, envigorizada para continuar con una tarea que toda la sociedad burguesa en algún momento vería como una absoluta aberración. En el trayecto Wilde no sólo perdería el control sobre su cuerpo, puesto que su carcelero sería el verdadero dueño durante dos años, sino también sobre lo más preciado y valioso para un artista: la independencia y la tranquilidad de espíritu para crear. Bastará leer "De Profundis" para darse cuenta de las enormes proporciones que tiene para Wilde el arrepentimiento, por todo el tiempo perdido al lado de Bosie cenando con panteras?

Finalmente, en este afán nuestro por entender al hombre, para recalar sus lecciones artísticas a nuestra época, no podemos concluir esta sección sin referirnos a sus ideas políticas, las que en realidad creemos, le causaron su caída y su desgracia final. Ampliaremos este tema un poco más adelante, entre tanto, anotemos que algunos críticos contemporáneos sostienen que, en todo lo que respecta a Óscar Wilde, los ingleses siempre se han equivocado. Sabemos hoy que, a pesar de que sus afeminadas maneras, su esteticismo y hedonismo a ultranza fueron el blanco de la burla de la prensa victoriana, y también de alguna prensa amarga y venenosa de los Estados 
Unidos (de San Francisco para ser preciso, durante su visita en 1882), lo que resultó más incómodo tanto para los oficiales del imperio británico, como para la burguesía aristocrática de algunos circulos culturales norteamericanos, fue la forma directa y veraz, con que Wilde abordó el problema irlandés. Contamos con fragmentos de sus conferencias en los Estados Unidos, en las cuales el escritor siempre que pudo, criticó al imperio británico, a la política migratoria de aquél, y de manera sutil y elegante insinuó que el socialismo era un ideario digno de tomar en cuenta para combatir la ocupación británica de Irlanda. Es cierto, durante su estadía en los Estados Unidos, aquellos circulos culturales que mencionamos arriba, sintieron que el poeta se burlaba de sus poses academicistas, vacías y burdas. A él, por su parte, la prensa de San Francisco lo hizo víctima del escarnio y la mofa caricaturesca. Pero el hombre asumió el asunto con estoicismo, con una inteligencia sólo digna de Óscar

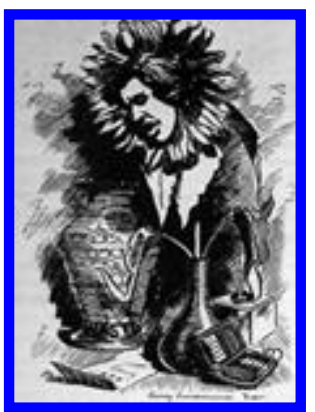

Wilde.

El hedonismo sincero de Wilde pudiera haber producido algún grado de acidez en los sectores más conservadores y vigilantes de la moral pública victoriana. Lo mismo que el lado oculto de su vida privada, atemperado por un matrimonio trágico y falaz, parecía atraer la curiosidad más morbosa del público británico de la época, porque rara vez alguien exponía su verdadera naturaleza sexual con tanta sinceridad como lo había hecho el escritor. Todavía estos ingredientes podían ser manejables en una corte de justicia. Pero que el arte por el arte fuera la excusa para promover sus verdaderas ideas políticas, hacían de nuestro poeta una presa fácil, como veremos más adelante, de los inveterados prejuicios políticos y culturales de la corona británica. Ser irlandés, rojo y maricón, 
eran indiscutiblemente tres componentes decisivos para hacer saltar en pedazos a cualquiera que se atreviera a criticar al venerable e intachable imperio británico. Lo más curioso de todo ésto es que Wilde amaba a su reina Victoria, y cada vez que podía celebraba los cumpleaños de ella, con la misma devoción que cualquier anciano británico, ciego creyente de la infalibilidad de su monarca.

\section{ÓSCAR WILDE: EL ESTETA.}

Con frecuencia, la enigmática visión de la vida que tenía Óscar Wilde, evoca en nosotros una capacidad particular para llevar hasta sus últimas consecuencias aquello en lo que creemos y en lo que sentimos. El esteticismo de Óscar Wilde tiene el tono de la ficción, del puente que se establece entre el sueño y la realidad. Vivir la vida como una obra de arte puede plantearle problemas a quien la aborda con la cordura que da la perpetua racionalización a que nos obliga la vida cotidiana ${ }^{10}$.

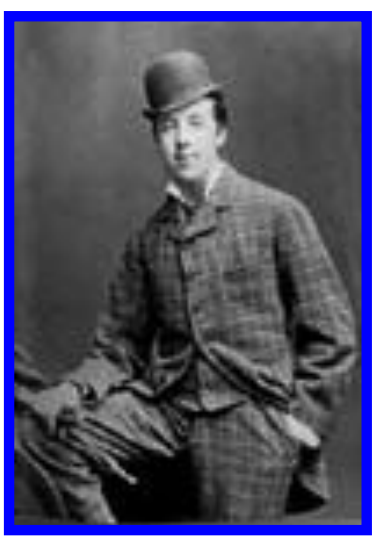
El arte por el arte, postulado central de algunos de los grandes teóricos de la estética pre-rafaelista como Walter Pater (18391894), y cuya influencia artística en Wilde fue decisiva, en apariencia, podía profundizar las contradicciones entre la amoralidad del arte y el supuesto compromiso que el artista debía tener con los problemas de su tiempo. Porque para Wilde no existían el libro pervertido o el libro virtuoso. Existían los libros bien o mal escritos. Y esta sola afirmación fue capaz de provocar un debate de grandes proporciones, que incluso se siente hoy día entre nosotros. 
El esteticismo de Óscar Wilde, su dandysmo, pertenecen a la era del imperialismo, a los sobrecogedores umbrales del siglo XX. No es el dandysmo de Charles Baudelaire por ejemplo, todavía bajo los influjos de una revolución francesa que no acaba su tarea, aun cuando la comuna de París de 1871, supuestamente, debió de haber llevado al colmo una herencia que en el presente recordamos con nostalgia y gratitud. El arte por el arte, como patrón ideológico, en el caso más que concreto de Oscar Wilde, es una estrategia de evasión, ante las evidencias contundentes de la fealdad de la sociedad industrial. En estos casos jamás el arte podrá imitar la vida.

Si partimos de la base de que el arte por el arte es una actitud irresponsable, sometida a los vaivenes del gusto literario y artístico de la época, o metida de plano en los caprichos estéticos del artista, eso sería ponerle límites muy serios a un conjunto de ideas que no se agotan en el culto por el objeto de arte, sino que va más allá y abarca también el grado de inserción que tenga el artista en su realidad social, política y cultural específica. Cuando Wilde sostenía que el arte era inútil, se refería precisamente a su supuesta banalidad, predicada por años por una burguesía pragmática y estéril, que sólo confiaba en la industria para producir "cosas útiles". Se refería también a los despropósitos socio-económicos del mismo, puesto que los afectos, las emociones y la soledad creativa del artista no están diseñadas para producir cosas útiles según el criterio de la burguesía, sino objetos bellos, capaces de evocar en el espectador la posibilidad de tener acceso a un mundo mejor. En ese sentido el arte es subversivo, pero sigue siendo inútil. Aunque el artista y su creación serían muy útiles para la burguesía si defendieran y estuvieran al servicio de sus intereses. 
La tesis del arte por el arte, no sólo como se expresó en la Inglaterra victoriana, sino también en la Francia del Segundo Imperio, generaba una serie de acaloradas discusiones sobre todo porque, si la revolución industrial había traído consigo una riqueza colosal para los poderosos, también se hizo acompañar por una pobreza aterradora. Tal tesis en este caso, era poco menos que frívola y superficial. Sin embargo, difícilmente el artista con sus creaciones podía modificar dicha situación. La pintura de los pre-rafaelistas no alteró un ápice los desmanes imperialistas británicos en la India, por ejemplo. O la humillante situación en la que se encontraba la mujer.

Sin embargo, en el ejemplo de Wilde como en el de muchos otros creadores de su época, el arte podía convertirse en un artefacto de poderosa influencia política y social, a partir de la fuerza y de la naturaleza del compromiso con que el artista se insertaba en la sociedad de su tiempo. De tal manera que, entre el buen decir de Wilde, y su verdadero hacer, la lógica dialéctica nos dice que son los resultados los que nos permiten medir la verdadera dimensión del impacto de sus creaciones, y los mismos son de tal magnitud que hoy podemos decir que existe una bibliografía cercana a los ocho mil títulos sobre su vida y su obra.

Durante su estadía en los Estados Unidos, en 1882, Wilde impartió conferencias sobre las distintas y variadas expresiones de la belleza, pero la sonoridad del recibimiento que le dieron no estuvo en proporción con los contenidos y las críticas que quiso hacer. La buena sociedad norteamericana parecía hacer derroche de su riqueza, pero no sucedía lo mismo en lo que respecta al buen gusto, la delicadeza, y el glamour en los disttintos escenarios que ofrecía la vida cotidiana. Como les hizo ver con cínica franqueza sus limitaciones, algunos escritores y críticos del autor lo encontraron 
presuntuoso e infatuado, pero rara vez escrutaron a profundidad lo que Wilde entendía por belleza, sentido estético y sensibilidad artística.

Esta clase de desacuerdos, por más esfuerzos que él hubiera hecho para atemperarlos y no perder la paciencia con el mal gusto de la pretenciosa y arrogante nueva burguesía industrial norteamericana, le enseñaron mucho y lo ubicaron de frente a la gran polémica del siglo: ¿Dónde reside el verdadero valor de una obra de arte? ¿Quién decide lo que es una obra maestra? Dos preguntas que, cómo decía Wilde, habían recibido una riquísima gama de respuestas, pero sobre las cuales cada vez sabíamos menos.

Hoy, cuando el valor de una pieza artística se mide por su cotización en la bolsa, el esteticismo de Wilde tendría muy poco que añadir, pero es un resonante llamado de atención. Por eso, en gran medida continúa con nosotros, porque tuvo el coraje de sostener que la belleza tenía valor en sí misma, y que no era un medio para enriquecer a su poseedor. La economía política del gusto nos enseña a fin de cuentas que la belleza, el talento, el ingenio no se poseen, somos poseídos por ellos. Una cosa que la inveterada burricia maquinista de la burguesía no vislumbró jamás. Su mundo de objetos útiles, su insaciable necesidad de cosas, de mercancías, ha jugado el papel de una plataforma muy efectiva para dinamizar al mundo de los marchantes, pero ha dejado libres, aunque sufrientes y exangües, a los creadores, sobre todo aquellos que

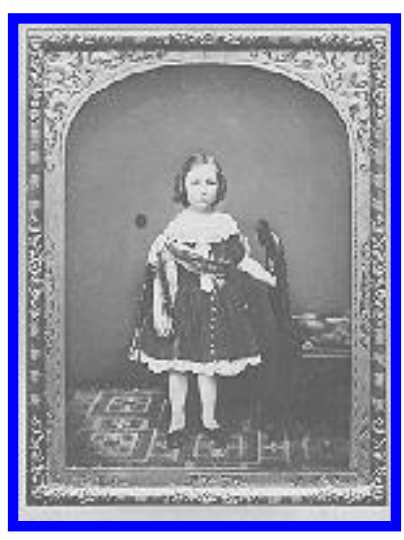
no se venden, así les vaya en ello la salud física y mental.

Por eso el esteticismo de Wilde como decíamos arriba, no se puede comprender fuera de su proyecto vital, el cual incluye su homosexualidad, su condición de irlandés y de soñador 
socialista. "El mapa del mundo estará incompleto si en él no incluimos al país de la Utopía"11. Aseveraciones como ésta eran las que le ocasionaban sus tórridos enfrentamientos con el orden burgués establecido. Porque siempre le gustó jugar al borde de los límites, víctima de las tentaciones y de la marginalidad. Tomar riesgos al filo del precipicio no sólo fue una idea que permeó su sexualidad, sino también sus creencias estéticas, las cuales aunque no tenían muy buena acogida por los teóricos del "establishment", eran frecuentemente recibidas con cierta simpatía por los sectores populares, como le sucedió con los mineros y las amas de casa en los Estados Unidos, cuando se dirigió a ellos para hablarles de la importancia de la belleza en nuestra vida cotidiana, y de la necesidad de tener una casa bien decorada y atendida. Si la mujer victoriana iba a ser ama y señora de los dominios de su hogar, entonces había que decorarlo de tal manera que se hiciera más tolerable la vida cotidiana en él.

Con el principio hegeliano en las manos, recogido en nuestros días y llevado hasta sus últimas consecuencias por un crítico como Lucáks, de que la belleza de un objeto no es un tema de discusión ontológica necesariamente, autores como Sir Edward Arnold, John Ruskin y Walter Pater, a quien ya nos referimos, le prepararon el terreno a Wilde para que su estética esencialista fuera más allá del simple placer cotidiano o instantáneo que pudiera producir una obra de arte. Tal tensión entre la cotidianidad y la eternidad no se resolvía con el hedonismo de los pre-rafaelistas, aunque las propuestas de Rossetti o Morris eran dignas de tomar en cuenta, sino, según Wilde, de acuerdo con la capacidad que tuviera un determinado artista de minar el terreno de la estética burguesa desde adentro. Bien sabemos que dicha tensión le reventó en la cara. Sin embargo, encontró seguidores en autores posteriores como Gide, Auden, Nabokov, 
Beckett, Mann y otros que supieron plantarse de manera frontal ante una estética burguesa que aspiraba a la legitimación esencialista del objeto, en la medida en que éste tarde o temprano terminaría convertido en mercancía.

En ningún lugar, finalmente, podemos ver con más claridad la textura de dicha tensión que en los diálogos que sostienen sus personajes dramáticos. El dialoguismo de Wilde, como diría Bakhtin, es un recurso mediante el cual el autor despliega a plenitud todas sus objeciones hacia la sociedad burguesa, pero tiene la fuerza particular, asumida con sutileza y elegancia, de revelar sus paradojas sin caer en la vulgaridad discursiva o panfletaria que sus temas pudieron haber provocado. Si el artista vive en los límites de la sociedad, y con regularidad puede ser confundido con un criminal, por su actitud rebelde y marginal, la burguesía hace lo mismo, sólo que se oculta tras una pasta de afeites a la cual hay que penetrar con el cincel de la crítica y la sensibilidad individuales. De aquí que el socialismo de Wilde apunte hacia el rescate del individuo antes que a cualquier masa social informe y primitiva. A continuación nos referiremos un poco al tema.

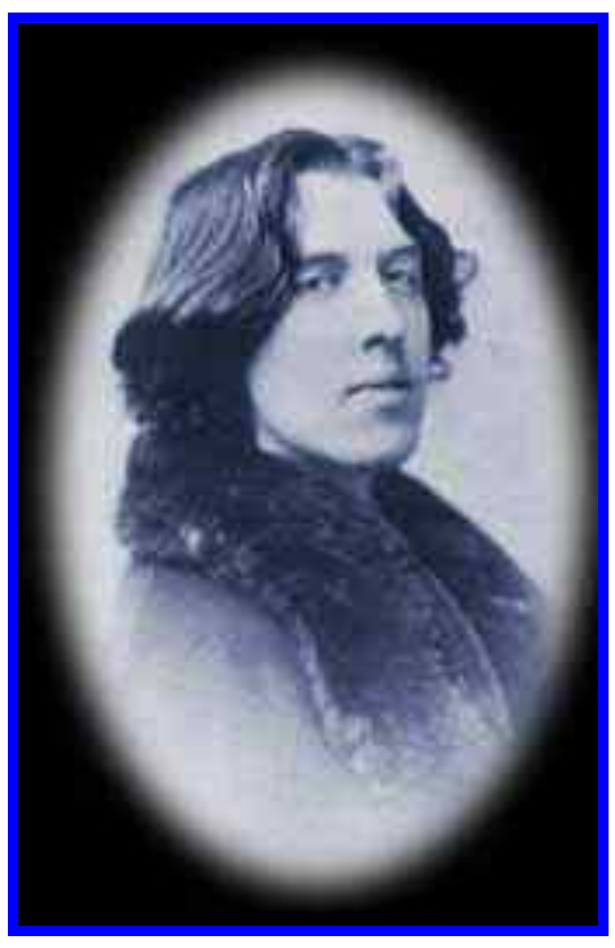

OSCAR WILDE: EL SOCIALISTA.

"La principal ventaja que se obtendría del establecimiento del socialismo, sería indudablemente que el socialismo nos relevaría de la sórdida necesidad de trabajar para otros, la que, en el presente estado de cosas, presiona tanto sobre 
casi todo el mundo. De hecho, casi nadie escapa $" 12$.

Wilde sostenía que en el socialismo el desarrollo del individuo, a la larga, devendría en un extraordinario beneficio para toda la comunidad. Pero era fundamental, ofrecerle a ese individuo las condiciones ideales para que su expansión y crecimiento como ser humano se dieran sin limitaciones de ninguna naturaleza. En su condición de irlandés católico, hijo de una mujer (Esperanza) dirigente dura y combativa del movimiento feminista, también líder lúcida y brillante de las tareas por la liberación de Irlanda, Wilde nunca separó su sueño de la posible construcción del socialismo de las luchas por la independencia de su país. Sostenía que la sensibilidad y profundidad de los celtas no tenían por qué estar sometidas a la frivolidad y al burdo sentido práctico de los teutones (sajones o ingleses). Estas ideas, desplegadas en varios de sus ensayos, pero notablemente en The soul of man under socialism (1891), le ocasionaron algunos problemas con la crítica literaria victoriana. A ésta, la Revolución Industrial le había creado el falso sentimiento de la infalibilidad del proyecto burgués de civilización, y por ello, el cánon victoriano estaba lubricado de arriba a abajo con la húmeda creencia de que todos los pueblos del planeta le merecían incondicional entrega. Húmeda en la sangre, el sudor y las lágrimas, de los trabajadores de las colonias, quienes durante la Primera Guerra Mundial (1914-1918) empezarían a inmolarse por una causa que no era la suya.

La Inglaterra victoriana es la del apogeo de la industrialización, pero también la del crecimiento de la clase trabajadora, de sus luchas, sus avances, retrocesos y conquistas. En la era del imperialismo, cuando las utopías sociales florecen como hongos por todas partes, puesto que la miseria que ha traído consigo la expansión 
capitalista en pro del enriquecimiento colosal de unos cuantos, no pasa inadvertida para aquellos con suficiente sensibilidad y sentido común como para percatarse sobre quién se beneficia y cómo legitima esos privilegios.

Las reflexiones de Wilde sobre la sociedad de su tiempo son portadoras de esa orientación. Pocos autores del período hicieron tanto para promocionarse a sí mismos, pero también pocos lograron penetrar tan a fondo lo que en realidad era la Inglaterra victoriana. Sus viajes a los bajos fondos de Londres, una ciudad con dos millones de pobres al iniciarse los noventa, se completaban con su conocimiento práctico y teórico sobre los círculos sociales más distinguidos de aquella.

Consecuente con su hipótesis de que el carisma, el buen vestir, la prudencia en las comidas y la templanza en los placeres eran el resultado de un conocimiento adquirido en un mano a mano con los excesos, Wilde hizo lo que estuvo a su alcance para vender su imagen, y con ello estaba dando el primer paso hacia la venta de sí mismo como mercancía artística, producto de la publicidad, una de las grandes aspiraciones del hombre contemporáneo. Todos seremos famosos por lo menos durante quince minutos de nuestras vidas, decía Warhol. Y de esta manera, Wilde saldó sus deudas con su pasado en Oxford, con una pizca de notoriedad.

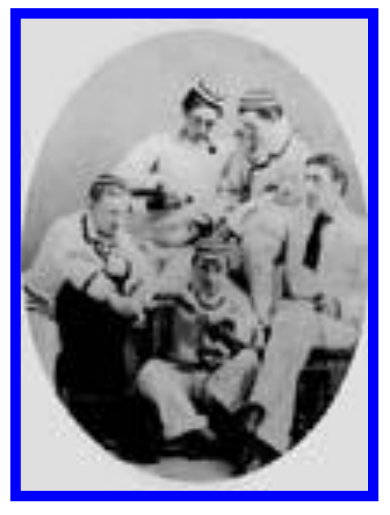

Porque sostenía que los dos grandes cambios de su vida habían tenido lugar cuando sus padres lo enviaron a Oxford, y cuando la sociedad lo envió a prisión. No podemos decir que estos dos acontecimientos fueran hitos decisivos en su discreto enfrentamiento con la burguesía victoriana, pero sí lo fueron en el diseño de su perfil como poeta y escritor, porque el material 
que ambas experiencias suplieron le facilitó un mejor conocimiento de sí mismo y por supuesto la creación de ese mundo literario personal en el que el único héroe visible era él mismo.

No debemos llamarnos a engaño atragantándonos con la creencia de que las utopías que sueña Wilde tienen algo que ver con el concepto totalitario que tiene Marx del socialismo. Es de notar que, a pesar de que el marxismo se sirvió con mucho de la sólida tradición racionalista burguesa, que se remonta a los inicios del siglo XVI, y que bien por ello lo podemos considerar como parte del pensamiento burgués occidental, aunque moleste a sus más severos defensores, nunca perdió, tal vez más bien exacerbó, la vena totalitaria de tal racionalismo. Puede resultar difícil de negar la vertiginosa propensión totalitaria del reinado de Victoria; ahí están las brutalidades de su imperio para probarlo. Precisamente es contra esa tiranía victoriana que Wilde escribe sus ensayos, sus historias para niños y sus dramas. Pero no se le enfrenta de una manera abierta y exultante. Su lucha contra la mojigatería, la falsa espiritualidad, y la frivolidad volátil de los victorianos está planteada en términos estéticos, de manera que es también estética la noción de socialismo que cultiva Wilde.

Pero aquí no hablamos de un socialismo melifluo y azucarado, sino de un socialismo de catacumba, marginal, que sueña con un mundo mejor para los desheredados de la tierra, los minoritarios, los criminales, los desajustados y los irracionales. En gran

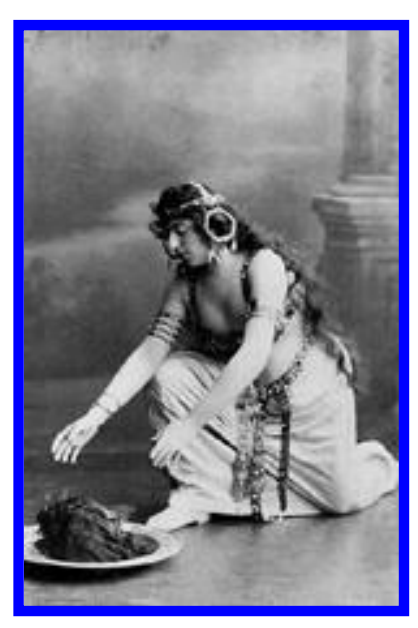

parte ese es el tributo que Wilde le rinde a los chulitos de los barrios bajos de Londres: soñar sus sueños y traducirlos en poesía, prosa y pensamiento. Pero como buen pequeño burgués, 
citadino y acomodaticio, también se cobra su precio: acostarse con ellos, aunque después le devuelvan el zarpazo.

La educación sentimental de Wilde bien puede valorarse a partir de su catalítico más notable, su relación con Lord Alfred Douglas; pero le haríamos una gran injusticia si hiciéramos algo igual con su ideario socialista y utópico, pues éste tiene una gestación más tribal, casi familiar, en el cual la atractiva figura de su madre es vertebral.

Wilde está más cerca de Tolstoi que de Bakhunin, y todavía más de los fabianos que de los marxistas. Pareciera feliz de estar al margen de las ruidosas discusiones que se suscitan al interior de la Segunda Internacional de los Trabajadores, definitivamente rasgada en vísperas de la Primera Guerra Mundial. Aún así, la vida de Wilde se extiende a lo largo de un período rico en acontecimientos sociales, políticos y culturales, que no le pasaron desapercibidos en su gran mayoría, y en los cuales, cuando fue requerido, tuvo una participación importante, como el asunto de la cacería de brujas que provocó el caso Dreyfus. Su participación en el "affaire" no está clara por completo, pero sabemos que con Emile Zola y otros grandes escritores de la época, hizo lo necesario para mostrarle al mundo el racismo y la intolerancia que había detrás de la condena de Alfred Dreyfus (1859-1935) por supuesta alta traición al ejército francés en favor de los alemanes. Su gran delito fue ser judio.

El individualismo de Wilde, sustentado sobre la sólida idea de que si la persona humana no dispone de condiciones materiales y espirituales para desplegarse a cabalidad abre el paso a muchas variantes de la esclavitud, tiene una vigencia y una vitalidad en nuestros días, que asombra por su frescura y su inmediatez. No se trata del individualismo rampante y explotador que predican el liberalismo y el neoliberalismo 
actuales, sino más bien de aquél que sostiene que si los seres humanos no sacan todo lo que tienen dentro, la sociedad se verá invadida por todos los vicios y consecuencias nefastas que traen consigo la frustración, las inhibiciones, la amargura y la represión. La belleza, el cultivo del espíritu, la solidaridad, serían los vehículos mediante los cuales los hombres y mujeres de la nueva Utopía harán posible la recuperación del individuo. "El estado fue concebido entonces para hacer lo útil, el individuo para realizar lo bello" decía Wilde, en una frase que recoge a la perfección su criterio sobre los distintos terrenos en que deben moverse ambos sujetos.

El individualismo burgués, cuyas raíces penetran en el egoísmo más elaborado, es objeto de crítica y sarcasmo por parte de Wilde. El argumenta que el hombre egoísta jamás tendrá conflictos con la máquina, porque ésta le completa como instrumento de producción, y culturalmete hablando, lo deja intacto desde el punto de vista moral. El ingeniero industrial, para usar un ejemplo, al estilo de los que soñaban Ford y Taylor, y que fue maravillosamente tipificado en los trabajos de Ayn Rand, es un sujeto sin contradicciones de ninguna especie, tan compacto que asusta su efectividad, para la cual todo lo no que genere mercancías es inútil. No era ese el tipo de individualismo en el que estaba pensando de Wilde.

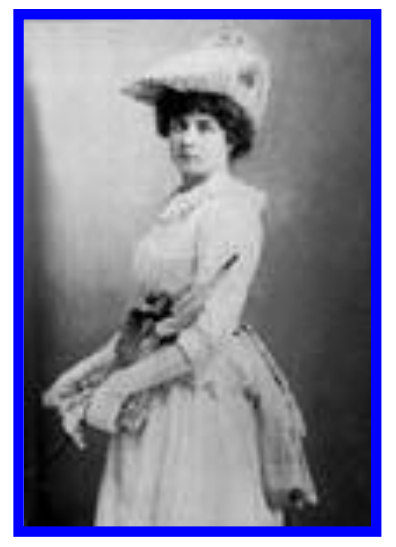

Uno quisiera pensar que el socialismo de Wilde es más sistemático, más y mejor articulado que muchas propuestas que circulaban por aquellos días, pero no pasa de ser una pose romántica, anti-colonialista y certeramente estética, nada más. Leerlo con los ojos de un marxista de nuestros días, puede llenarnos de frustraciones, pues podríamos ponerlo a decir cosas 
que nunca dijo, ni pensó remotamente. Casi nos inclinamos por argumentar que para Wilde el arte y la individualidad, esa noción específica que tiene del individualismo, son interdependientes. Ya decíamos páginas atrás, que él intuyó la diferencia operativa entre individuo e individualidad. Para fines estéticos tal distinción es central, pues la burguesía tiene una idea del individuo que en nada se parece a la que estuvo trabajando Wilde hasta su muerte en 1900.

Sonará formalista lo que vamos a señalar, pero a veces es útil este tipo de juegos semiológicos. Si separamos al sueño del soñador, nos daremos cuenta que en un ensayo como "The soul of man..." el contenido utopista del trabajo lleva la dirección de hacerle notar al lector que sin él, ningún progreso social o cultural es posible. Wilde no sistematiza su sueño, sólo piensa en los cambios que experimentará el soñador cuando esa nueva sociedad se vislumbre en el horizonte. Esto es perfectamente lógico, a partir del andamiaje estético que Wilde se ha construido. En sus "historias socialistas para niños" la belleza de las narraciones, de los temas, del lenguaje, de los personajes, nos impiden de primera entrada darnos cuenta que en casi todas ellas, se parte de postulados binarios: justo-injusto, bueno-malo, bello-feo, egoísta-generoso, y así en casi todos sus cuentos. No podía haber sido de otra manera, la lógica formal, de fuerte sabor aristótelico, es la plataforma sobre la que reposa la visión del mundo de la burguesía colonialista de los tiempos de Wilde, y él, para bien o para mal, fue educado por ella, a pesar de que su decadentismo esteticista le haya grangeado su mala voluntad. Con serias dificultades la burguesía tolera de nuevo en sus filas, a quienes la traicionan.

\section{UNA REFLEXIÓN FINAL.}


Con este ensayo nos hemos dado cuenta de un asunto: en la vida y obra de Oscar Wilde hay tres pecados y una virtud. Su homosexualidad, sus ideas socialistas y su procedencia nacional, junto a su capacidad para soñar, para diseñar utopías, hicieron del proyecto vital de este hombre algo paradigmático en el desarrollo personal de algunos de los grandes creadores de este siglo.

Pero esa confluencia de factores no se da de forma idéntica en todos ellos, puesto que la especificidad histórica define el perfil que tendrá ese proyecto existencial en particular. ¿Será posible una comparación entre Óscar Wilde y el escritor cubano disidente Reinaldo Arenas (1943-1990), una de las grandes plumas de la literatura latinoamericana de este siglo? En este último caso, la bronca de Arenas no es contra el proyecto cultural burgués, es contra otro supuestamente inspirado en los ideales del socialismo. Pero él también fue víctima de otra forma de totalitarismo: aquél que se sirve a manos llenas de las grandes y buenas lecciones de la historia. Es difícil escamotear la idea de que, al fin y al cabo, la honestidad le demanda a cualquier historiador no eludir las grandes y abrumadoras semejanzas que se pueden establecer entre el fascismo y el stalinismo.

Pero el ejemplo que nos dejan artistas como Arenas, a partir de la luz que arrojan las lecciones de autores como Wilde, es que desde la perspectiva cultural, a pesar de las distintas expresiones que puede asumir el autoritarismo, éste sigue siendo portador de la misma naturaleza opresiva, brutal e intolerante, sin importar los parámetros espacio-temporales que estemos manejando. Tampoco importa el dictador de marras, al fin y al cabo la prepotencia, la arrogancia y la mentalidad paternalista de fuertes ecos medievales, es la misma, así se trate de la reina Victoria o de Mussolini. 
Wilde como Arenas y otros similares, nos dejan la gran enseñanza de que la insolencia imperialista y totalitaria, con sus distintas expresiones, puede llegar a límites insospechados, cuando los grupos que la sustentan sienten que las instituciones y los aparatos que los legitiman pueden rodar por los suelos. Aquí, el dogma, el catecismo y toda la liturgia civil que las hizo posibles entran en crisis y de esta manera, entonces, se ponen en movimiento los mecanismos requeridos para sacar de circulación a esa persona o personas, que amenazan con traerse abajo la nueva forma de pensamiento y disciplina eclesiásticos, que ha venido al mundo con la monarquía de una persona o de una maquinaria partidista.

En su lucha contra esa maquinaria, un hombre como Wilde se arriesgó pero perdió su vida. Sólo el arte lo salvó del olvido irreparable que trae consigo el ostracismo cultural a que se ven sometidos los artistas e intelectuales que osan enfrentar al monstruo de la dictadura, en cualquiera de sus distintos disfraces. Razón tenía Proust al sistematizar aquella maravillosa idea de que solamente con el arte se recupera el tiempo perdido. Con Wilde el asunto es todavía más grave porque no tuvo tiempo suficiente para rescatarse a sí mismo, y cuando la tragedia lo alcanzó apenas comprendió lo que le estaba sucediendo. Dos años en prisión no fueron suficientes para despejar el enigma en que se había convertido su vida. Nos damos cuenta de que fue poco lo que alcanzó a entender, cuando al salir de prisión lo primero que el hombre hace es buscar a su antiguo amante, precisamente quien de alguna manera fue el principal instrumento de su desgracia. ¿O será que las razones del corazón no atienden a razones? Cien años después de su muerte, recordamos de Wilde su lírica terquedad emocional, una que 
Proust, Gide y Arenas después de él, convirtieron en el mecanismo artístico más eficaz para sellar su ingreso al siglo veinte. 


\section{$\underline{\text { CITAS. }}$}

\footnotetext{
${ }^{1}$ Historiador costarricense (1952). Premio nacional (1998) de la Academia de Geografía e Historia de Costa Rica.

2 "Y todos los hombres matan lo que aman, que lo oiga todo el mundo,

${ }^{3}$ En nuestro libro 1898-1902. El legado de la guerra hispano-antillano-norteamericana (Heredia, Costa Rica. EUNA. 2000. En prensa) nosotros tratamos este asunto con un poco más de profundidad.

${ }^{4}$ WILDE, Óscar. Cartas a Lord Alfred Douglas. (Barcelona: Tusquets. Segunda edición a cargo de Luis Antonio de Villena. 1997. Carta del martes 15 de junio de 1897) Pp. 128-129.

${ }^{5}$ Idem. “The Critic as Artist”. ("El crítico artista. Diálogo"). Plays, Prose Writings and Poems

(Cambridge, England: Everyman. 1996 ) Pp.97-163. Para una excelente versión al español véase la colección titulada JORGE LUIS BORGES. BIBLIOTECA PERSONAL Ensayos y Diálogos. (Buenos Aires: Ediciones Argentina. 1985) Pp. 12-100.

6 "It often happened that when we thought we were experimenting on others we were really experimenting on ourselves". The Picture of Dorian Gray and Other Writings by Oscar Wilde (New York. Bantam Books. 1982) P.53.

${ }^{7}$ En un libro nuestro que está por salir, ampliamos estos asuntos. La Fantasía del Poder. Mujeres, Imperios y Civilización (en prensa).

${ }^{8}$ EVANS, Richard. Las feministas. Los movimientos de emancipación de la mujer en Europa, América y Australasia. 1840-1920. (Madrid: Siglo XXI. 1980). P. 35.
}

${ }^{9}$ WILDE, Óscar. Epistola: In Carcere et Vinculis ("De Profundis"). (Barcelona: Seix Barral. 1981. Traducción de José Emilio Pacheco.) Pp. 36-37.

${ }^{10}$ WALSH, David. “Oscar Wilde's lasting significance”. En WORLD SOCIALIST WEB SITE. PUBLISHED BY THE INTERNATIONAL COMMITTEE OF THE FOURTH INTERNATIONAL 28 July 1997. (http://www.wsws.org/arts/1997/jul1997/wilde 1.shtml.).

${ }^{11}$ WILDE, Oscar. Idem. Op. Cit. 1996. Pp.28-29.

${ }^{12}$ Idem. Loc. Cit.

DR. RODRIGO QUESADA MONGE (1952), historiador costarricense, premio nacional de historia (1998) de la Academia de Geografía e Historia de su país. Tiene publicaciones en diversas revistas del continente, y varios libros sobre historia económica y social de América Central y del Caribe. 